\title{
The Science of Mosquitoes: Youth Perceptions, Engagements, and Learning from a Skype in the Classroom Science Communication Program
}

A. McLeod-Morin'1 , P. Beattie², W. Stone ${ }^{3}$, K. Kent ${ }^{4}$, J. Loizzo ${ }^{5}$, R. Telg 6

\begin{abstract}
This study examined the impact of a live, interactive electronic field trip (EFT), called Scientist Online: The Science of Mosquitoes via the Streaming Science platform and Skype in the Classroom network for connecting university entomologists with middle and high school youth around the world. More than 150 students viewed the program, and 60 answered post-quantitative and qualitative questions regarding their perceptions of the EFT and knowledge related to mosquitoes. Students reported an increased knowledge about mosquitoes, mosquito-borne illness, mosquito-borne illness prevention and protection, entomology and related careers, and the mosquito life-cycle. Future research should determine how interactive, synchronous video programs with scientists can impact participants' behavior intentions, specifically for making lifestyle choices based in science, as well as decisionmaking for improving their health and the planet.
\end{abstract}

\section{Keywords}

Electronic field trip, Skype in the Classroom, science communication, solutions-focused communication, STEM careers

1. Ashley McLeod-Morin, Communications Coordinator, UF/IFAS Center for Public Issues Education in Agriculture and Natural Resources, Doctoral Student, University of Florida, 1408 Sabal Palm Drive $2^{\text {nd }}$ Floor, PO Box 110320 Gainesville, FL 32611, ashleynmcleod@ufl.ede, https://orcid.org/0000-0002-8649-9783

2. Peyton Beattie, Doctoral Candidate, University of Florida, PO Box 110540, Gainesville, FL 32611, pbeattie@ufl.edu, https://orcid.org/0000-0002-0677-4600

3. Whitney Stone, Graduate Assistant, University of Florida, PO Box 110540, Gainesville, FL 32611, whitney.stone@ufl.edu, https://orcid.org/0000-0003-3090-5751

4. Kevin Kent, Doctoral Candidate, University of Florida, PO Box 110540, Gainesville, FL 32611, kevin.kent@ufl.edu, https://orcid.org/0000-0002-0239-6817

5. Jamie Loizzo, Assistant Professor, University of Florida, PO Box 112060, Gainesville, FL 32611, jloizzo@ufl.edu, https://orcid.org/0000-0002-5575-2918

6. Ricky Telg, Professor, Director of UF/IFAS Center for Public Issues Education in Agriculture and Natural Resources, University of Florida, PO Box 110320 Gainesville, FL 32611, rwtelg@ufl.edu, https://orcid.org/0000-0002-8729-1634 


\section{Introduction and Problem Statement}

The mosquito has played an instrumental role in shaping human history, the global economy, and world health (Winegard, 2019). Mosquitoes can transmit several dangerous and, sometimes, deadly diseases, such as malaria (Ruckert et al., 2017). In addition to the negative impacts on human and animal health, the diseases also cause significant economic impacts. It is estimated that the 2016 Zika outbreak cost between $\$ 7$ billion and $\$ 18$ billion for affected countries (United Nation Development Programme, 2017).

To address the severe implications caused by mosquitoes, health agencies are working to increase public education and awareness initiatives through science communication campaigns (Porse et al., 2015). The public can informally learn about topics related to science through science communication, which should engage individuals in a way that will lead to a more informed society about science issues and topics (Dijkstra \& Gutteling, 2012; Kleinman \& Powell, 2010). As the public engages more with topics related to science, such as mosquitos, they become better equipped to make informed choices concerning policy, personal health, and family finances and can participate in discussions on ecological, economical, and social issues (Nelkin, 1995; Treise \& Weigold, 2002).

As public health agencies aim to broaden their engagement with a variety of diverse audiences to increase awareness and mobilize behavior change around mosquitoes and related topics, it is imperative youth audiences are included and reached in interactive and educational ways. Electronic field trips (EFTs) are a proven delivery model for introducing PK-12 classrooms to remote locations, topics, and careers and have the potential to include entomology content (McCrea, 2012). The diffusion of EFTs should be further explored to determine how this innovation can impact agricultural education and communication.

\section{Theoretical and Conceptual Framework}

Scientists today have more opportunities than ever before to engage in two-way communication through online media, such as video conferencing, that can reach diverse audiences around the globe and impact individual's science literacy (Davies \& Hara, 2017; Lundy et al., 2006). EFTs are an example of a two-way online channel for connection and dialogue for live, synchronous, interactive video for science engagement (Cassady et al., 2008; Loizzo et al., 2019; Tuthill \& Klemm, 2002). EFTs have increased in popularity in recent years, as schools have cut travel budgets and teachers have identified constricting logistical barriers such as time, transportation, and academic testing demands that prevent them from taking physical class field trips to external locations (Adedokun et al., 2011; Parker et al., 2010; Stoddard, 2009). EFTs straddle the formal and non-formal education because they include an out-ofschool location connecting with students inside a typical classroom environment (Adedokun et al., 2012a; Adedokun et al., 2012b; Tuthill \& Klemm, 2002; Loizzo et al., 2019; NRC, 2015). 
The Microsoft Educator Skype in the Classroom network includes thousands of educators from around the world in an online community to connect their learners with guest speakers, including scientists (Skype, 2020). Teachers who have participated in Skype in the Classroom have indicated youth are excited, engaged, and can ask a variety of questions of experts through Skype (Foote, 2008; McCrea, 2012; Morgan, 2013). Participating students are often encouraged to ask questions of the experts throughout the Skype sessions. Exposing youth to insects, such as mosquitoes, fosters an appreciation and interest that may not otherwise be encouraged (Shipley \& Bixler, 2019). However, most youth are not exposed to insects beyond the life cycle.

A combination of theory and concepts guided this study, including solutions-focused science communication, Social Cognitive Theory (SCT), vicarious learning, and Social Cognitive Career Theory (SCCT) guided this study. SCCT and vicarious learning informed the design choice of connecting youth with scientists vicariously through Skype in the Classroom. SCCT guided the researchers' conceptualization of impacts of the EFT on participants' STEM topical and career interest, while solutions-focused communication informed the program content development and assessment for examining specific learning goals of mosquito-borne illness prevention and protection.

Roots of solutions-focused communication were first established by Chalmers (1959) as he studied journalists who brought attention to corruption and explained how solutions-focused journalists did not simply provide information, but also recommended solutions to problems. Gyldensted (2015) furthered the notion of solutions-focused communication, as she established the need for journalists to report on news beyond crises, but also on news that brings attention to advancements in society.

Through SCT, Bandura $(1977,1986)$ proposed an individual's personal factors, environment, and a person's learning or behavior have a direct, relationship to each other (Bandura, 1986; 2001). Vicarious learning through mass media permits audiences to learn a vast amount of information about behaviors and social norms, ultimately offering new ways of thinking and approaching behavior (Bandura, 2001). Moreover, individuals' motivation to perform the observed learned behavior hinges on if the individuals value the outcome to a behavior (Bandura, 2001).

SCCT (Lent et al., 1994) is founded in the work of Bandura's SCT (1977) and Hackett and Betz's (1981) theory of translation work and examines human agency in career development with understudied populations (Lent \& Brown, 2019). SCCT in STEM-related research can help better understand students' goal orientation toward STEM careers (Dutta et al., 2015).

\section{Purpose}

The purpose of this study was to examine the impacts of a live, interactive EFT called Scientist Online: The Science of Mosquitoes via the Streaming Science platform and Skype in the 
Classroom network for connecting university entomologists with middle and high school youth around the world. The objectives that guided this study included the following:

1. Describe students' perceptions of the mosquito EFT.

2. Describe students' perceived knowledge before and after the mosquito EFT.

\section{Methods}

The Science of Mosquitoes EFT program was streamed via Skype in the Classroom and lasted 3545 minutes (Beattie et al., 2020). This project was a part of a larger grant project funded by the Florida Department of Health (FDOH) to the University of Florida Institute of Food and Agricultural Sciences Center for Public Issues Education in Agriculture and Natural Resources (PIE Center).. The purpose of the larger grant project was to increase public awareness related to mosquitoes, mosquito-borne illnesses, and mosquito control. The learning objectives were for students to (a) describe the mosquito life cycle, habitats, and physical traits; (b) list mosquito-borne diseases; and (c) summarize mosquito-borne illness prevention and protection/control methods. Researchers and Skype in the Classroom promoted the program broadly and recruited approximately 150 students in grades from $4^{\text {th }}$ to $7^{\text {th }}, 11^{\text {th }}$ to $12^{\text {th }}$, and adult learners participated in the EFT: Florida (1 classroom), Pennsylvania (2 classrooms), Canada ( 2 classrooms), and Pakistan (an all-male college-aged boarding school).

A retrospective post-survey was used to collect individual answers from students about their perceived knowledge before and after the EFT, as well as their personal perceptions of the program. The population of interest for this study were all students who participated in The Science of Mosquitoes EFT program. A total of 60 students across the six classrooms completed the survey, approximately a $40 \%$ response rate.

The first section of the questionnaire asked the students to Please share your thoughts on 'The Science of Mosquitoes' Skype in the Classroom call given five points (i.e., 1 = strongly disagree, 5 = strongly agree). The second section of the questionnaire addressed students' level of knowledge retrospectively about mosquito related topics given four points (i.e., $1=$ none, $4=$ high). The open-ended section of the questionnaire asked the students to type/write a response to the question prompt. An example of one open-ended prompt is what are the top three things you learned from the program? The questionnaire was administered through the teachers of the participating students either via the online, Qualtrics software or by paper, depending on computer accessibility.

The data from the two fixed response sections was analyzed through descriptive statistics. We calculated individual item means and standard deviations and reported answers for the two question sets. The following real limits of the scale were used to interpret the data answering the question Please share your thoughts on 'The Science of Mosquitoes' Skype in the Classroom call: $1.00-1.49=$ strongly disagree, $1.50-2.49=$ disagree, $2.50-3.49=$ neutral, $3.50-4.49=$ agree, $4.50-5.00=$ strongly agree. The real limits of the scale used to answer the retrospective 
before and after knowledge question were as follows: $1.00-1.49=$ none, $1.50-2.49=$ low, $2.50-3.49=$ medium, $3.50-4.00=$ high .

We analyzed the open-ended responses through a deductive coding process, based on the learning objectives of The Science of Mosquitoes EFT program. For instance, codes included lifecycle, prevention, protection, and careers. We used the predetermined codes to categorize the student responses and calculated the frequency of the code's appearance in the students' answers.

A limitation of this study is the small sample size. The exploratory nature of this study does not allow for the results to be generalized beyond the sample of this study. The age of participants also varied widely, ranging from fourth grade to young adult. This variation may result in limitations in the data.

\section{Findings}

The student respondents reported the highest means for the items The scientist did a good job answering questions $(M=4.35, S D=.78)$, The scientist was knowledgeable about the topic $(M=$ $4.33, S D=.93)$, I would recommend the program to other classes $(M=4.27, S D=.86)$, and It is important to learn about mosquito-borne illnesses $(M=4.25, S D=.80)$, respectively (see Table 1). The students rated I learned about careers in entomology from the scientist $(M=3.22, S D=$ $1.03)$ and I like entomology $(M=2.78, S D=1.03)$ the lowest according to mean scores.

\section{Table 1}

Students' perceptions of the mosquito EFT

\begin{tabular}{lcc}
\hline & $M$ & $S D$ \\
\hline The scientist did a good job answering questions. & 4.35 & .78 \\
The scientist was knowledgeable about the topic. & 4.33 & .93 \\
I would recommend this program to other classes. & 4.27 & .86 \\
It is important to learn about mosquito-borne illnesses. & 4.25 & .80 \\
The scientist communicated at a level that I understood. & 4.10 & .78 \\
The scientist gave an interesting demonstration to explain mosquito research. & 4.05 & 1.00 \\
The scientist was interesting. & 3.92 & .77 \\
The program was easy to see. & 3.85 & .92 \\
The scientist talked about something I did not already know. & 3.80 & 1.07 \\
The program was easy to hear. & 3.78 & .89 \\
I thought the topic was interesting. & 3.75 & .84 \\
It is important that we learn about mosquitoes. & 3.68 & .93 \\
I learned about careers in entomology from the scientist. & 3.22 & 1.03 \\
I like entomology. & 2.78 & 1.03 \\
\hline
\end{tabular}

Note. Real limits of the scale: $1.00-1.49=$ strongly disagree, $1.50-2.49=$ disagree, $2.50-3.49=$ neutral, 3.50 - $4.49=$ agree, $4.50-5.00=$ strongly agree 
Students rated their knowledge about mosquitoes before The Science of Mosquitoes EFT to be the highest $(M=2.44, S D=.74)$. See Table 2. After The Science of Mosquitoes EFT, the students ranked their knowledge of the mosquito life cycle the highest $(M=3.57, S D=.57)$. The students reported their knowledge of entomology careers to be the lowest both before $(M=1.41, S D=$ .71) and after $(M=2.55, S D=.99)$ The Science of Mosquitoes EFT.

\section{Table 2}

Students' perceived knowledge before and after the mosquito EFT

\begin{tabular}{lcccc}
\hline & \multicolumn{2}{c}{ Before } & \multicolumn{2}{c}{ After } \\
\cline { 2 - 5 } My knowledge before/after the 'The Science of Mosquitoes'.. & $M$ & $S D$ & $M$ & $S D$ \\
\hline Mosquitoes & 2.44 & .74 & 3.43 & .57 \\
Mosquito life cycle & 2.20 & 1.07 & 3.57 & .57 \\
Mosquito-borne illness prevention and protection & 1.93 & .99 & 3.04 & .84 \\
Mosquito-borne illness & 1.91 & .96 & 3.06 & .67 \\
Entomology & 1.51 & .85 & 2.80 & .97 \\
Entomology careers & 1.41 & .71 & 2.55 & .99 \\
\hline
\end{tabular}

Note. Real limits of the scale: $1.00-1.49=$ none, $1.50-2.49=10 \mathrm{w}, 2.50-3.49=$ medium, $3.50-4.00=$ high

When asked to provide their own typed/written answers to the question What are the top three things you learned from the program?, students discussed mosquito-borne diseases/illnesses, mosquito control, the life cycle or breeding of mosquitoes, types/species of mosquitoes, entomology/entomology careers, mosquitoes biting or sucking blood, the mosquito habitat, mosquito's diet, and how mosquitoes are dangerous/not dangerous. The topics students discussed the most for the item List the top three things you learned from the program were the life cycle or breeding of mosquitoes $(n=35)$, mosquito-borne diseases/illnesses $(n=34)$, and types/species of mosquitoes $(n=21)$. For the question Where do mosquitoes live?, the students discussed water-related habitats, all around the world, grass, and warm/hot places. The answer most frequently provided was water-related habitats ( $n=$ $36)$, followed by all around the world $(n=7)$, warm/hot places $(n=5)$, and grass $(n=2)$.

Students provided answers to the question What are two actions you can do to protect yourself from mosquito-borne illness? The students most frequently reported bug spray or repellent $(n=$ $40)$, followed by using window screens or mosquito nets in your home ( $n=12)$, getting rid of standing water or keeping mosquitoes from breeding $(n=11)$, and wearing longer clothing $(n=$ 10).

\section{Conclusions, Discussion, and Recommendations}

Exploring students' perceptions and perceived knowledge gain through the participation of an EFT program provides greater understanding of the impacts EFT participation can have on student education. Students who participated in The Science of Mosquitoes EFT answered questions about their personal perceptions and knowledge. In this study, students reported improved perceived knowledge in almost all topics that were elements of the EFT program, 
including entomology careers and the mosquito life-cycle. These findings align with previous literature that posited EFTs can culminate excitement and interest in science-related topics, such as entomology (Foote, 2008; McCrea, 2012; Morgan, 2013). The EFT content was solutions-focused in nature, which could have also aided the students' engagement (Gyldensted, 2015).

While statistical significance of knowledge gain cannot be determined, it can be noted that students had some level of increased knowledge of mosquitoes, the mosquito life cycle, mosquito-borne illness, mosquito-borne illness prevention and protection, entomology, and entomology careers from their reported self-perceived knowledge before and after the EFT. The only topic students indicated having a high level of knowledge of after the EFT was the mosquito life-cycle. The mosquito life-cycle and breeding were the answer students reported most frequently learning from the EFT program in the open-ended question. The scientists used toy-like replica models of the mosquito life cycle to teach students about the life-cycle. This was the only portion of the program that used replica models and possibly could have enhanced student learning. Shipley and Bixler (2019) determined that most elementary and secondary education curriculum commonly included insect life cycles, which might have aided student comprehension in this study since it was likely they had been exposed to that information previously.

Recommendations for future research include continued study of EFT impacts on youth and adult science literacy and knowledge. Additional research questions in the future should include how interactive, synchronous video programs with scientists can impact participants' behavior intentions, specifically for making lifestyle choices based in science, as well as decision-making for improving their health and the planet.

As results revealed that life cycle portion and learning objective of the program, which featured physical insect props, was the only portion that students indicated a high level of knowledge, future EFTs should continue to show some photos and videos, as well as real life props, including handheld, physical demonstrations to explain a concept. This method appears to be more favorable for youth online audiences. Hence, live EFTs should have a live demonstration and not rely on videos or multimedia material, which appeared to be less engaging.

SCCT was included in the guiding framework for this study. However, according to data analysis, entomology careers appeared to be students' least interested/engaged portion of the program. Future programs should more specifically and seamlessly incorporate detailed, targeted moments and content to more intentionally create excitement about career pathways, as well as show a variety of careers and role models from diverse backgrounds. Future researchers should then explore how different career content and role models might impact students' career interest. Additionally, future EFT programs should more directly investigate vicarious learning impacts on students' STEM interest in self-efficacy. 


\section{Acknowledgements}

Prevent \& Protect: Mosquito Control Messages for Your Community is supported by the SmithLever Special Needs Competitive Grant Program [grant award no. 2016-41210-25622] from the USDA National Institute of Food and Agriculture. Any opinions, findings, conclusions, or recommendations expressed in this work are those of the author(s) and do not necessarily reflect the view of the U.S. Department of Agriculture. This work is also supported by a grant from the Florida Department of Health. The research reported in this article supports the mission of the University of Florida Institute of Food and Agricultural Sciences' (UF/IFAS) Center for Public Issues Education in Agriculture and Natural Resources.

\section{References}

Adedokun, O. A., Hetzel, K., Parker, L. C., Loizzo, J. L., Burgess, W. D., \& Robinson, J. P. (2012a). Using virtual field trips to connect students with university scientists: core elements and evaluation of Purdue zipTrips ${ }^{\mathrm{TM}}$. Journal of Science Education and Technology, 21(5), 607-618. http://dx.doi.org/10.1007/s10956-011-9350-z

Adedokun, O. A., Parker, L. C., Loizzo, J.L., Burgess, W. D., \& Robinson, J. P. (2012b). Factors influencing participant perceptions of program impact: lessons from a virtual fieldtrip for middle-school students. Journal of Extension [Online], 49(6) Article 6FEA8. http://www.joe.org/joe/2011december/a8.php

Adedokun, O. A., Parker, L. C., Loizzo, J. L., Burgess, W. D., Robinson, J. P. (2011). A field trip without buses: connecting your students to scientists through a virtual visit. Science Scope, 34(9).

Ary, D., Jacobs, L. C., Sorensen, C., \& Walker, D. A. (2014). Introduction to research in education (9th ed.). Wadsworth Cengage Learning.

Bandura, A. (1977). Self-efficacy: Toward a unifying theory of behavioral change. Psychological Review, 84(2), 191-215. http://doi.org/10.1037/0033-295X.84.2.191

Bandura, A., (1986). Social foundations of thought and action: A social cognitive theory. Prentice-Hall.

Bandura, A. (2001). Social cognitive theory of mass communication. Media Psychology, 3 265299.

Beattie, P. N., Loizzo, J. L., Kent, K. W., Krebs, C. L., Suits, T. E., \& Bunch, J. C. (2020, January 30February 5). Leveraging Skype in the Classroom for science communication: A Streaming Science - Scientist online approach. [Paper presentation]. National Agricultural Communication Symposium (NACS), Louisville, KY, United States. 
Cassady, J.C., Kozlowski, A., \& Kornmann, M. (2008). Electronic field trips as interactive learning events: Promoting student learning at a distance. Journal of Interactive Learning Research, 19(3), 439-454. https://www.learntechlib.org/p/24187/

Chalmers, D.M. (1959). The muckrakers and the growth of corporate power: A study in constructive journalism. The American Journal of Economics and Sociology, 18(3), 295311. https://www.jstor.org/stable/3484760

Davies, S.R., \& Hara, N. (2017). Public science in a wired world: How online media are shaping science communication. Science Communication, 39(5), 563-568. http://doi.org/10.1177/1075547017736892

Dijkstra, A. M., \& Gutteling, J. M. (2012). Communicative aspects of the public-science relationship explored: Results of focus group discussions about biotechnology and genomics. Science Communication, 34(3), 363-391. http://doi.org/10.1177/1075547011417894

Dutta, A., Kang, H. J., Kaya, C., Benton, S. F., Sharp, S. E., Chan, F., da Silva Cardoso, E., \& Kundu, M. (2015). Social-cognitive career theory predictors of STEM career interest and goal persistence in minority college students with disabilities: A path analysis. Journal of Vocational Rehabilitation, 43(2), 159-167. http://doi.org/10.3233/JVR-150765

Foote, C. (2008). See me, hear Me: Skype in the classroom. School Library Journal, 54(1), 42-43.

Gyldensted, C. (2015). From mirrors to movers: Five elements of positive psychology in constructive journalism. Group Publishing.

Hackett, G., \& Betz, N. E. (1981). A self-efficacy approach to the career development of women. Journal of Vocational Behavior, 18(3), 326-336.

Kleinman, D. \& Powell, M. (2010). Consensus conference on nanotechnology. In D. H. Guston (Ed.), Encyclopedia of nanoscience and society (pp. 117-117). Sage Publications Ltd. http://doi.org/10.4135/9781412972093.n67

Lent, R. W., \& Brown, S. D. (2019). Social cognitive career theory at 25: Empirical status of the interest, choice, and performance models. Journal of Vocational Behavior, 115(103316), 1-14. https://doi.org/10.1016/i.jvb.2019.06.004

Lent, R. W., Brown, S. D., \& Hackett, G. (1994). Toward a unifying social cognitive theory of career and academic interest, choice, and performance. Journal of Vocational Behavior, 45(1), 79-122.

Loizzo, J., Harner, M. J., Weitzenkamp, D. J., \& Kent, K. (2019). Electronic field trips for science engagement: The Streaming Science model. Journal of Applied Communications, 103(4). https://doi.org/10.4148/1051-0834.2275 
Lundy, L. K., Ruth, A., Telg, R., \& Irani, T. (2006). It takes two: Public understanding of agricultural science and agricultural scientists' understanding of the public. Journal of Applied Communications, 90(1), 55-68. http://doi.org/10.4148/1051-0834.1290

McCrea, B. (2012). Skype takes students where no school bus can go. THE Journal (Technological Horizons In Education), 39(5), 18.

Morgan, H. (2013). Technology in the classroom: Using Skype for exciting projects. Childhood Education, 89(3), 197-199.

National Academies of Science, Engineering, and Medicine (NASEM). (2017). Communicating science effectively: A research agenda. The National Academies Press. http://doi.org/10.17226/23674

Navarro, M., Tome, K., \& Aldemita, R. (2014). Academics and scientists as biotech [Paper presentation]. 13th International Public Communication of Science and Technology Conference, Salvador, Brazil. http://www.pcst2014.org/pcst proceedings/artigos/mariechel navarro kristine tome rhodora aldemit a individual papers.pdf

Nelkin, D. (1995) Selling science: How the press covers science and technology. W.H. Freeman and Company.

Parker, L. C., Adedokun, O. A., Loizzo, J. L., \& Burgess, W. D. (2010). Purdue zipTrips ${ }^{\mathrm{TM}}$ : Connecting students and scientists through electronic field trips. IL Spectrum, 36(2), 3643.

Porse, C.C., Kramer, V.L., Yoshimizu, M.H., Metzger, M.E., Hu, R., Padgett, K., \& Vugia, D. (2015). Public health responses to Aedes aegypti and Ae. Albopictus mosquitoes invading California, USA. Emerging Infectious Diseases, 21(10). https://dx.doi.org/10.3201\%2Feid2110.150494

Ruckert, C., Weger-Lucarelli, J., Garcia-Luna, S. et al. (2017). Impact of simultaneous exposure to arboviruses on infection transmission by Aedes aegypti mosquitoes. Nature Communications, 8(15412). http://doi.org/10.1038/ncomms15412

Schunk, D.H. (2012). Learning theories: An educational perspective (6 $6^{\text {th }}$ ed.). Pearson.

Shipley, N.J., \& Bixler, R.D. (2019). An unconventional approach to fostering entomological literacy. American Entomologist, 65(1), 19-23. http://doi.org/10.1093/ae/tmz013

Stoddard, J. (2009). Toward a virtual field trip model for the social studies. Contemporary Issues in Technology and Teacher Education, 9(4), 412-438. https://www.learntechlib.org/p/28305/ 
Treise, D., \& Weigold, M. F. (2002). Advancing science communication: A survey of science communicators. Science Communication, 23(3), 310-322. http://doi.org/10.1177/107554700202300306

Tuthill, G. \& Klemm, E. B. (2002). Virtual field trips: Alternatives to actual field trips. International Journal of Instructional Media, 29(4), 453-468. https://go.galegroup.com/ps/i.do?p=AONE\&sw=w\&u=googlescholar\&v=2.1\&it=r\&id=G ALE\%7CA97173049\&sid=googleScholar\&asid=d9bcc634

United Nations Development Programme. (2017). A socio-economic impact assessment of the Zika virus in Latin America and the Caribbean. https://www.undp.org/content/undp/en/home/librarypage/hiv-aids/a-socio-economicimpact-assessment-of-the-zika-virus-in-latin-am.html

Weaver, K.N., Hill, J.M., Martin, G.D., Paterson, I.D., Coetzee, J.A., \& Hill, M.P. (2017). Community entomology: Insects, science and society. Journal for New Generation Sciences, 15(1), 176-186. https://journals.co.za/docserver/fulltext/newgen_v15 n1 a13.pdf?expires=157971864 3\&id=id\&accname=guest\&checksum=7F54E0C71922EC9BEA7C3C3E34FBBCB2

Winegard, T. C. (2019). The mosquito: A human history of our deadliest predator. Penguin Random House LLC.

(C) 2020 by authors. This article is an open access article distributed under the terms and conditions of the Creative Commons Attribution license (http://creativecommons.org/licenses/by/4.0/). 